\title{
A COMPARISION OF FENTANYL AND NALBUPHINE IN ATTENUATING HAEMODYNAMIC RESPONSE TO DIRECT LARYNGOSCOPY AND ENDOTRACHEAL INTUBATION- A STUDY OF 90 CASES
}

\section{Dr. Nehal Chandra}

\section{Dr. Atul B. Vyas}

\section{Dr. Parasmani*}

\author{
Senior Resident, Department Of Anaesthesia, V.M.M.C And Safdarjung \\ Hospital, New Delhi.
}

Associate Professor, Department Of Anaesthesia, B.J.M.C., Ahmedabad.

Senior Resident, Department Of Anaesthesia, V.M.M.C And Safdarjung Hospital, New Delhi. *Corresponding Author

ABSTRACT BACKGROUND: Laryngoscopy and endotracheal intubation is known to cause hemodynamic changes which are usually increase in heart rate and blood pressure.Various drugslike beta blockers,opioids and alpha 2 agonists have been tried to attenuate these hemodynamic responses. AIMS: To compare the effects of Fentanyl and Nalbuphine in attenuating the stress response to directlaryngoscopy and endotracheal intubation. METHODS- After informed consent we studied 90patients, all posted for surgery under general anaesthesia between the age group of 15 to 60 . We conducted the study over a period of 6 months. Data was collected and analysed. Three groups of patients were made Group $\bar{A}-$ Inj. Fentanyl $2 \mu \mathrm{g} / \mathrm{kg}$ ivGroup B- Inj. Nalbuphine $0.2 \mathrm{mg} / \mathrm{kg}$ ivGroup C- Inj Normal Saline 10cc. Only ASA I and II patients were included in the study.Haemodynamic changes were noted by meticulous monitoring and analyzed. RESULTS: The hemodynamic stress response to laryngoscopy and endotracheal intubation in the form of increased heart rate,systolic blood pressure, diastolic blood pressure and mean blood pressure were less with Fentanyl as compared to Nalbuphine and Normal Saline. CONCLUSION: Fentanyl is more effective than Nalbuphine in attenuating hemodynamic stress response tolaryngoscopy and endotracheal intubation.

\section{KEYWORDS : Laryngoscopy, Intubation, Fentanyl, Nalbuphine.}

\section{INTRODUCTION}

Laryngoscopy and endotracheal intubation is known to cause hemodynamic changes which are usually increase in heart rate and blood pressure.It is associated with rise in concentrations of serum catecholaminesand is associated with frequent complications. ${ }^{[11.12]}$ Direct laryngoscopy and endotracheal intubation lead to mechanical and chemical stimuli. Mechanical stimuli reflexly affect cardiovascular and respiratory system while chemical stimuli lead to hypertension, tachycardia and arrhythmias. These hemodynamic changes occur due to epi-pharyngeal and laryngo-pharyngeal stimulation which causes reflex increase in sympatho-adrenal activity and sympathetic discharge. Increase in blood pressure and heart rate is usually transient, variable and unpredictable.Potent analgesics with lesser side effects and longer duration of action are a must to decrease such stress responses and further complications while induction and intubation. ${ }^{[3,5,6]}$. Various druglike beta blockers,opioids and alpha 2 agonists have been tried in order to attenuate these hemodynamic response. This study aims to compare the effects of Fentanyl and Nalbuphine in reducing the stress response that occurs during direct laryngoscopy and endotracheal intubation.

\section{MATERIALS AND METHODS}

Institutional ethical approval was obtained. After informed consent we studied 90patients, all posted for surgery under general anaesthesia between the age group of 15 to 60 . We conducted the study in a period of 6 months at Civil Hospital, Ahmedabad. Data was collected and analyzed. Three groups of patients were made Group A - Inj. Fentanyl $2 \mu \mathrm{g} / \mathrm{kg}$ ivGroup B- Inj. Nalbuphine $0.2 \mathrm{mg} / \mathrm{kg}$ ivGroup C- Inj Normal Saline $10 \mathrm{cc}$. Only ASA I and II patients were included in the study. Known cases of bronchial asthma, Hypertension, IHD, patients with atrial/ventricular arrhythmias, second/third degree A-V conduction block, patients with severe hemodynamic instability, patients on beta adrenergic antagonist therapy/calcium channel blockers, patients with anticipated difficult airway were excluded from the study. A thorough history was taken and a detailed examination was carried out.Patients were subjected to routine and relevant investigations. The procedure was explained to the patient and written informed consent wastaken.On arrival to the operation theatre, intravenous access was established with 18G cannula. All patients were preloaded with $8-10 \mathrm{ml} / \mathrm{kg}$ crystalloid. All patients were pre-medicated with Inj. Glycopyrrolate $0.004 \mathrm{mg} / \mathrm{kg}$ i.v. and Inj.Ondansetron 0.15 $\mathrm{mg} / \mathrm{kg}$ i.v.Standard Monitoring was applied and baseline pulse rate, systolic blood pressure(SBP), diastolic blood pressure(DBP), mean arterial blood pressure(MAP) and $\mathrm{SpO}_{2}$ were recorded.The patients were pre oxygenated for 5 mins using $100 \%$ oxygen with Bain's circuit.

- Group A received Inj. Fentanyl $2 \mu \mathrm{g} / \mathrm{kg}$ diluted in $20 \mathrm{ml} \mathrm{NS}$ injected slowly over $10 \mathrm{~min}$ before induction

- Group B received Inj. Nalbuphine $0.2 \mathrm{mg} / \mathrm{kg}$ before induction

- Group C received 10 cc Normal Saline.

Induction of anaesthesia was carried out using Inj. Thiopentone Sodium 5-7 mg/kg and Inj. Succinlycholine $2 \mathrm{mg} / \mathrm{kg}$.Intubation was carried out using an appropriate size ET tube.Throat packing, positioning and surgical incision were with-held till completion of recording. Anaesthesia was maintained using $50 \%$ oxygen, $50 \%$ nitrous oxide, Sevoflurane and Inj.Vecuronium Bromide $0.08 \mathrm{mg} / \mathrm{kg}$ i.v.On completion of surgery, patient was reversed using Inj.Glycopyrrolate $0.008 \mathrm{mg} / \mathrm{kg}$ i.v. and Inj. Neostigmine $0.05 \mathrm{mg} / \mathrm{kg}$ i.v. Patients were watched for any complications like bradycardia, hypotension, arrhythmias, bronchospasm during intraoperative and postoperative period.

\section{Statistical Analysis}

All patients data were recorded. Data was expressed as mean values \pm standard deviation (SD). Quantitative data was analyzed using t-test and qualitative by chi square test. Statistical calculations were carried out using Microsoft Office Excel 2010 and Graph Pad Prism 6.05 (quickcalc) Software(Graph pad software inc. La Jalla CA USA). Changes in hemodynamic variables from baseline and a comparison of means were analyzed by paired t-test for each time interval. A p-value $<0.05$ was considered statistically significant.p value $>0.05$ was considered non-significant.

\section{Observations}

90 patients between the age group of 15 to 60 years belonging to ASA class I and II for various elective surgeries under 
general anesthesia at our institute were randomly selected and divided by computer generated numbers into 3 groups with 30 patients each.

TABLE 1: Age wise distribution

\begin{tabular}{|l|l|l|l|c|c|c|}
\hline & & & & \multicolumn{3}{|c|}{ pvalue } \\
\hline & Group A & Group B & Group C & AB & BC & AC \\
\hline Age in Years & $41.03 \pm$ & $43.2 \pm$ & $44.46 \pm$ & 0.454 & 0.664 & 0.186 \\
& 9.82 & 12.30 & 10.05 & & & \\
\hline
\end{tabular}

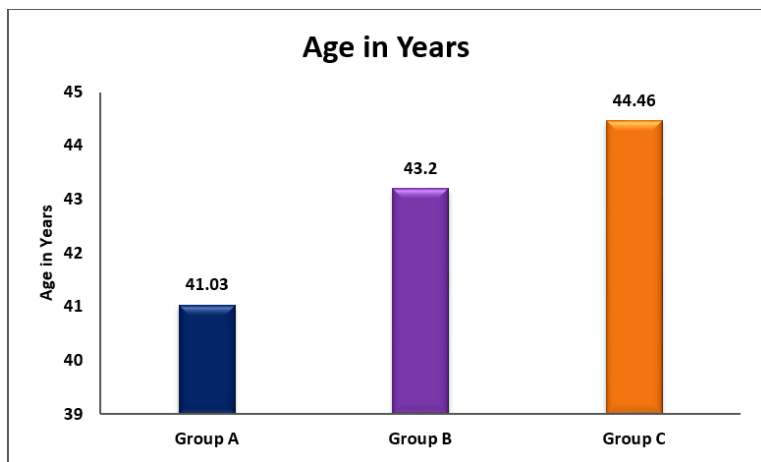

All the three groups were comparable age wise with no significant variations $(\mathrm{p}>0.05)$.

TABLE 2: Sex wise distribution

\begin{tabular}{|l|l|l|l|}
\hline & Group A & Group B & Group C \\
\hline Male & $17(56.6 \%)$ & $18(60 \%)$ & $14(46.6 \%)$ \\
\hline Female & $13(43.3 \%)$ & $12(40 \%)$ & $16(53.3 \%)$ \\
\hline Total & 30 & 30 & 30 \\
\hline
\end{tabular}

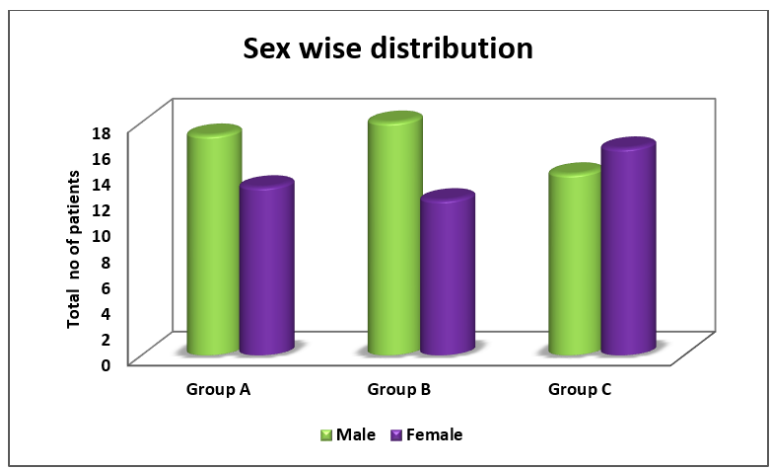

There was no significant variation $(p>0.05)$ between the three groups when compared for sex wise distribution.

TABLE 3: Heart rate wise distribution

\begin{tabular}{|c|c|c|c|c|c|c|}
\hline & & & & \multicolumn{3}{|c|}{ pvalue } \\
\hline & Group $\bar{A}$ & Group B & Group C & $\overline{A B}$ & BC & $\overline{A C}$ \\
\hline Baseline & $\begin{array}{l}82.93 \pm \\
5.83\end{array}$ & $\begin{array}{l}82.26 \pm \\
6.18\end{array}$ & $\begin{array}{l}82.3 \pm \\
5.94\end{array}$ & 0.669 & 0.626 & 0.948 \\
\hline Premed & $\begin{array}{l}85.16 \pm \\
6.17\end{array}$ & $\begin{array}{l}84.73 \pm \\
5.98\end{array}$ & $\begin{array}{l}84.6 \pm \\
5.97\end{array}$ & 0.783 & 0.932 & 0.719 \\
\hline nduction & $\begin{array}{l}86.43 \pm \\
6.14\end{array}$ & $\begin{array}{l}86.3 \pm \\
6.01\end{array}$ & $\begin{array}{l}85.86 \pm \\
5.88\end{array}$ & 0.933 & 0.779 & 0.717 \\
\hline Intub & $\begin{array}{l}86.63 \pm \\
6.11\end{array}$ & $\begin{array}{l}86.96 \pm \\
6.27\end{array}$ & $\begin{array}{l}86.90 \pm \\
5.78\end{array}$ & 0.836 & 0.966 & 0.863 \\
\hline $1 \mathrm{MIN}$ & $\begin{array}{l}93.67 \pm \\
5.74\end{array}$ & \begin{tabular}{|l|}
$77.63 \pm$ \\
6.08
\end{tabular} & $\begin{array}{l}104.47 \pm \\
6.06\end{array}$ & 0.012 & 0.000 & 0.000 \\
\hline $2 \mathrm{MIN}$ & $\begin{array}{l}96.7 \pm \\
5.88\end{array}$ & $\begin{array}{l}102.3 \pm \\
6.26\end{array}$ & $\begin{array}{l}108.5 \pm \\
5.95\end{array}$ & 0.001 & 0.000 & 0.000 \\
\hline $3 \mathrm{MIN}$ & $\begin{array}{l}101.6 \pm \\
6.19\end{array}$ & $\begin{array}{l}109.2 \pm \\
6.37\end{array}$ & $\begin{array}{l}114.5 \pm \\
5.98\end{array}$ & 0.000 & 0.000 & 0.000 \\
\hline $5 \mathrm{MIN}$ & $\begin{array}{l}99 \pm \\
5.94\end{array}$ & \begin{tabular}{|l|}
$106.1 \pm$ \\
5.91
\end{tabular} & $\begin{array}{l}112.53 \pm \\
6.02\end{array}$ & 0.000 & 0.000 & 0.000 \\
\hline $10 \mathrm{MIN}$ & $\begin{array}{l}83.53 \pm \\
6.35\end{array}$ & $\begin{array}{l}83.93 \pm \\
5.83\end{array}$ & $\begin{array}{l}83.6 \pm \\
6.18\end{array}$ & 0.800 & 0.669 & 0.870 \\
\hline
\end{tabular}

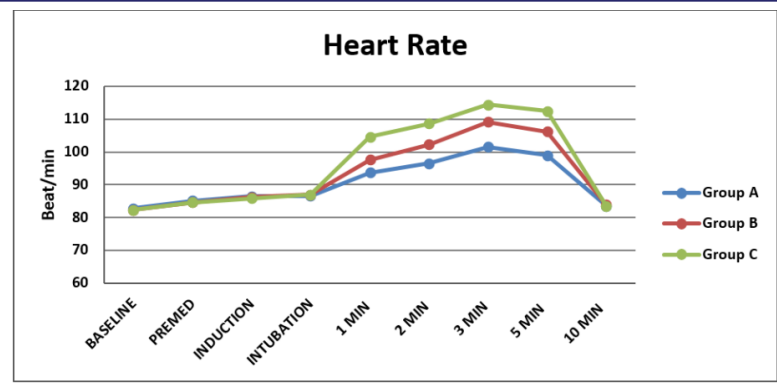

TABLE 4: Systolic blood pressure wise distribution

\begin{tabular}{|c|c|c|c|c|c|c|}
\hline & & & & \multicolumn{3}{|c|}{ p Value } \\
\hline & Group $\bar{A}$ & Group B & Group C & $\overline{A B}$ & BC & $\overline{A C}$ \\
\hline Baseline & $\begin{array}{l}107.67 \pm \\
6.19\end{array}$ & \begin{tabular}{|l|}
$107.83 \pm$ \\
5.91
\end{tabular} & $\begin{array}{l}107.73 \pm \\
6.28\end{array}$ & 0.915 & 0.950 & 0.967 \\
\hline Premed & \begin{tabular}{|l|}
$108.8 \pm$ \\
6.09
\end{tabular} & $\begin{array}{l}108.33 \pm \\
6.11\end{array}$ & $\begin{array}{l}108.17 \pm \\
6.12\end{array}$ & 0.768 & 0.598 & 0.817 \\
\hline Induction & \begin{tabular}{|l|}
$112.4 \pm$ \\
5.88
\end{tabular} & \begin{tabular}{|l|}
$112.8 \pm$ \\
5.98
\end{tabular} & $\begin{array}{l}112.27 \pm \\
6.10\end{array}$ & 0.795 & 0.733 & 0.932 \\
\hline Intubation & $\begin{array}{l}114.87 \pm \\
5.83\end{array}$ & $\begin{array}{l}115.9 \pm \\
6.09\end{array}$ & \begin{tabular}{|l|}
$115.4 \pm$ \\
6.04
\end{tabular} & 0.983 & 0.751 & 0.762 \\
\hline $1 \mathrm{~min}$ & $\begin{array}{l}120.57 \pm \\
5.69\end{array}$ & $\begin{array}{l}126.23 \pm \\
6.11\end{array}$ & $\begin{array}{l}134.07 \pm \\
6.14\end{array}$ & 0.000 & 0.000 & 0.000 \\
\hline $2 \mathrm{~min}$ & $\begin{array}{l}123.13 \pm \\
5.85\end{array}$ & $\begin{array}{l}132.03 \pm \\
5.93\end{array}$ & $\begin{array}{l}147.1 \pm \\
5.86\end{array}$ & 0.000 & 0.000 & 0.000 \\
\hline $3 \mathrm{~min}$ & $\begin{array}{l}128.77 \pm \\
6.27\end{array}$ & $\begin{array}{l}137.57 \pm \\
6.06\end{array}$ & $\begin{array}{l}158.03 \pm \\
5.83\end{array}$ & 0.000 & 0.000 & 0.000 \\
\hline $5 \mathrm{~min}$ & $\begin{array}{l}125.03 \pm \\
6.26\end{array}$ & $\begin{array}{l}130.8 \pm \\
6.07\end{array}$ & $\begin{array}{l}139.93 \pm \\
6.16\end{array}$ & 0.001 & 0.000 & 0.000 \\
\hline $10 \mathrm{~min}$ & $\begin{array}{l}115.47 \pm \\
6.11\end{array}$ & $\begin{array}{l}115.43 \pm \\
6.39\end{array}$ & $\begin{array}{l}115.83 \pm \\
5.91\end{array}$ & 0.984 & 0.802 & 0.813 \\
\hline
\end{tabular}

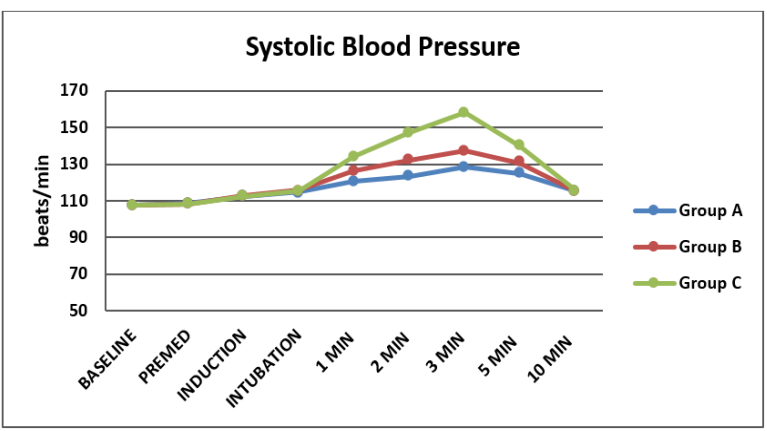

TABLE 5: Diastolic blood pressure wise distribution

\begin{tabular}{|l|l|l|l|c|c|c|}
\hline & & & \multicolumn{3}{|c|}{ p value } \\
\hline & Group A & Group B & Group C & AB & BC & AC \\
\hline Baseline & $83.27 \pm$ & $82.57 \pm$ & $82.93 \pm$ & $\mathbf{0 . 6 3 5}$ & $\mathbf{0 . 8 1 1}$ & 0.828 \\
& 5.67 & 5.68 & 6.16 & & & \\
\hline Premed & $84.57 \pm$ & $84.13 \pm$ & $84.37 \pm$ & 0.722 & 0.828 & 0.897 \\
& 5.84 & 5.73 & 6.07 & & & \\
\hline Induction & $85.47 \pm$ & $85.17 \pm$ & $85.6 \pm$ & $\mathbf{0 . 8 4 1}$ & 0.778 & 0.931 \\
& 5.79 & 5.76 & 6.10 & & & \\
\hline Intubation & $87.2 \pm$ & $87.03 \pm$ & $87.37 \pm$ & $\mathbf{0 . 9 1 2}$ & $\mathbf{0 . 8 3 1}$ & $\mathbf{0 . 9 1 7}$ \\
& 5.74 & 5.91 & 6.14 & & & \\
\hline 1 min & $93.77 \pm$ & $98.03 \pm$ & $103.5 \pm$ & $\mathbf{0 . 0 0 8}$ & $\mathbf{0 . 0 0 0}$ & 0.000 \\
& 6.18 & 5.87 & 6.10 & & & \\
\hline 2 min & $95.5 \pm$ & $100.97 \pm$ & $105.47 \pm$ & $\mathbf{0 . 0 0 1}$ & $\mathbf{0 . 0 0 6}$ & $\mathbf{0 . 0 0 0}$ \\
& 6.24 & 6.08 & 6.09 & & & \\
\hline 3 min & $99.07 \pm$ & $105.5 \pm$ & $109.5 \pm$ & $\mathbf{0 . 0 0 0}$ & $\mathbf{0 . 0 1 4}$ & $\mathbf{0 . 0 0 0}$ \\
& 5.98 & 6.11 & 6.05 & & & \\
\hline 5 min & $96.3 \pm$ & $102.57 \pm$ & $107.5 \pm$ & $\mathbf{0 . 0 0 0}$ & $\mathbf{0 . 0 0 3}$ & 0.000 \\
& 6.10 & 5.95 & 5.91 & & & \\
\hline 10 min & $84.33 \pm$ & $84.9 \pm$ & $84.57 \pm$ & $\mathbf{0 . 7 0 6}$ & $\mathbf{0 . 8 2 0}$ & 0.877 \\
& 5.85 & 5.61 & 5.67 & & & \\
\hline
\end{tabular}




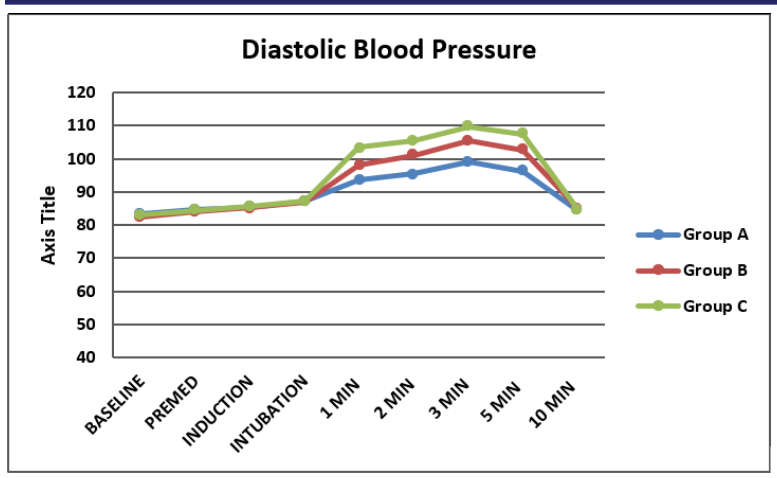

TABLE 6: Meam arterial blood pressure wise distribution

\begin{tabular}{|l|l|l|l|c|c|c|}
\hline & & & \multicolumn{3}{|c|}{ p value } \\
\hline & Group A & Group B & Group C & AB & BC & AC \\
\hline Baseline & $91.4 \pm$ & $91 \pm$ & $91.16 \pm$ & 0.773 & 0.914 & 0.864 \\
& 5.86 & 5.75 & 6.13 & & & \\
\hline Premed & $92.64 \pm$ & $92.33 \pm$ & $92.7 \pm$ & 0.743 & 0.714 & 0.966 \\
& 5.84 & 5.88 & 6.04 & & & \\
\hline Induction & $94.44 \pm$ & $94.38 \pm$ & $94.46 \pm$ & 0.929 & 0.948 & 0.983 \\
& 5.78 & 5.76 & 6.03 & & & \\
\hline Intubation & $96.42 \pm$ & $96.32 \pm$ & $96.23 \pm$ & 0.947 & 0.966 & 0.914 \\
& 5.74 & 5.95 & 6.10 & & & \\
\hline 1 min & $102.7 \pm$ & $107.43 \pm$ & $113.69 \pm$ & 0.003 & 0.000 & 0.000 \\
& 5.98 & 5.91 & 6.18 & & & \\
\hline 2 min & $104.71 \pm$ & $111.32 \pm$ & $119.34 \pm$ \\
6.02 & 0.000 & 0.000 & 0.000 \\
& 6.15 & 6.02 & & & \\
\hline 3 min & $108.97 \pm$ & $116.19 \pm$ & $125.68 \pm$ \\
6.01 & 0.000 & 0.000 & 0.000 \\
& 6.08 & 6.01 & & & \\
\hline 5 min & $105.88 \pm$ & $111.98 \pm$ & $118.36 \pm$ & 0.000 & 0.000 & 0.000 \\
& 6.19 & 6.09 & 5.92 & & & \\
\hline 10 min & $94.66 \pm$ & $95.08 \pm$ & $94.99 \pm$ & 0.792 & 0.964 & 0.825 \\
& 5.90 & 5.76 & 5.75 & & & \\
\hline
\end{tabular}

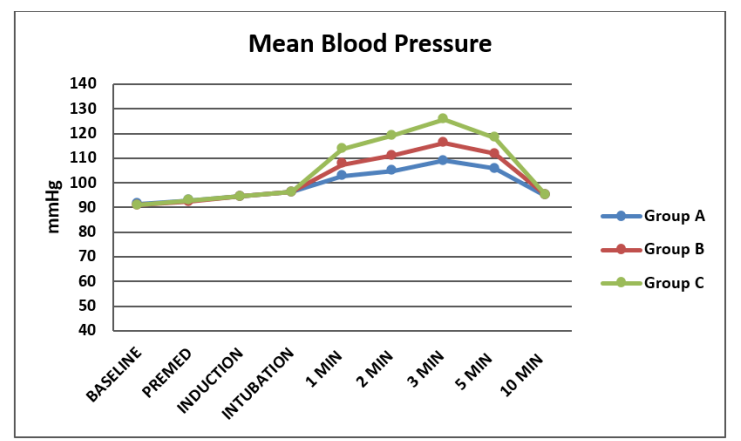

TABLE 7: Spo2 wise distribution

\begin{tabular}{|c|c|c|c|c|c|c|}
\hline & & & & \multicolumn{3}{|c|}{ p value } \\
\hline & Group A & Group B & Group C & $\overline{\mathrm{AB}}$ & $\mathrm{BC}$ & $\overline{A C}$ \\
\hline Baseline & $\begin{array}{l}99.47 \pm \\
0.51\end{array}$ & $\begin{array}{l}99.43 \pm \\
0.5\end{array}$ & $\begin{array}{l}99.53 \pm \\
0.51\end{array}$ & 0.799 & 0.447 & 0.613 \\
\hline Premed & $\begin{array}{l}99.53 \pm \\
0.51\end{array}$ & $\begin{array}{l}99.47 \pm \\
0.51\end{array}$ & $\begin{array}{l}99.43 \pm \\
0.5\end{array}$ & 0.617 & 0.799 & 0.447 \\
\hline Induction & $\begin{array}{l}99.43 \pm \\
0.5\end{array}$ & $\begin{array}{l}99.53 \pm \\
0.51\end{array}$ & $\begin{array}{l}99.53 \pm \\
0.51\end{array}$ & 0.447 & 1.000 & 0.447 \\
\hline Intubation & $\begin{array}{l}99.47 \pm \\
0.51\end{array}$ & $\begin{array}{l}99.47 \pm \\
0.51\end{array}$ & $\begin{array}{l}99.47 \pm \\
0.51\end{array}$ & 1.000 & 1.000 & 1.000 \\
\hline $1 \mathrm{~min}$ & \begin{tabular}{|l|}
$99.53 \pm$ \\
0.51 \\
\end{tabular} & \begin{tabular}{|l|}
$99.47 \pm$ \\
0.51 \\
\end{tabular} & \begin{tabular}{|l|}
$99.53 \pm$ \\
0.51 \\
\end{tabular} & 0.613 & 0.613 & 1.000 \\
\hline $2 \mathrm{~min}$ & $\begin{array}{l}99.47 \pm \\
0.51\end{array}$ & $\begin{array}{l}99.53 \pm \\
0.51\end{array}$ & $\begin{array}{l}99.47 \pm \\
0.51\end{array}$ & 0.613 & 0.613 & 1.000 \\
\hline $3 \mathrm{~min}$ & $\begin{array}{l}99.47 \pm \\
0.51\end{array}$ & $\begin{array}{l}99.53 \pm \\
0.51\end{array}$ & $\begin{array}{l}99.47 \pm \\
0.51\end{array}$ & 0.613 & 0.613 & 1.000 \\
\hline $5 \mathrm{~min}$ & \begin{tabular}{|l|}
$99.53 \pm$ \\
0.51 \\
\end{tabular} & \begin{tabular}{|l|}
$99.47 \pm$ \\
0.51
\end{tabular} & \begin{tabular}{|l|}
$99.53 \pm$ \\
0.51 \\
\end{tabular} & 0.613 & 0.613 & 1.000 \\
\hline $10 \mathrm{~min}$ & $\begin{array}{l}99.53 \pm \\
0.51\end{array}$ & $\begin{array}{l}99.53 \pm \\
0.51\end{array}$ & $\begin{array}{l}99.47 \pm \\
0.51\end{array}$ & 1.000 & 0.613 & 1.000 \\
\hline
\end{tabular}

\section{DISCUSSION}

A series of hemodynamic changes take place during laryngoscopy and endotracheal intubation. These include tachycardia, hypertension and arrhythmias. $\bar{A}$ control over these haemodynamic changes is a major challenge to anaesthesiologist. These changes are reported tobe greatest immediately after intubation andlast for 5-10 minutes .If no specific measures are taken to prevent ${ }^{[17]}$ hemodynamic response of laryngoscopy, the heart ratecan increase by $20 \%$ to $45 \%$ depending on the methodof induction and systolic blood pressure canincrease by $36 \%$ to $45 \%$.To blunt these ${ }^{[17,18]}$ responses, various methods have been triedlike topical application of local anaesthetic, infiltration, nerve blocks, adrenergic blockers, vasodilators, calcium channel blockers, 2 agonists $^{[19-23]}$. But thesedrugs have no role for induction and maintenance of anaesthesia and can also causes dangerous complications.Narcotics have advantage of having peri-operative role in anaesthesia.

They can be used as sole or supplementary agent for induction of anaesthesia. Narcotics are very commonly used for intra-operative analgesia, therefore there is no additional cost involved. Fentanyl is available in our country since 1998 and hasvarious advantages like absence of histamine release andbronchospasm, cardio-stability, rapid onset and short duration of action.

Nalbuphine is also cardiostable, potent analgesic, has minimum side effects in the dose of $0.2-0.4 \mathrm{mg} / \mathrm{kg}$ and its actions start within 2-3 minutes.

In our study we compared the effects of Fenatnyl, Nalbuphine and Normal Salinein attenuating hemodynamic stress response during laryngoscopy and endotracheal intubation. For this study of 90 patients under the age group of 15 to 60 years of either sex belonging to ASA class I and II posted for various surgery in general anaesthesia were randomly assigned three different groups after applying inclusion and exclusion criteria. All the groups were comparable in age and sex as shown in table 1 and 2. There was no statistical significance between the 3 groups.

\section{Hemodynamic parameters}

\section{(1) Heart rate(HR)}

As shown in table 3,baseline of mean heart rate were comparable of the 3 groups with no significant variations ( $p>0.05$ ).Changes in heart rate after giving the drugs were also not significant between the 3 groups $(p>0.05)$.There was increase in heart rate after intubation in all the three groups with maximum increase in group $C(104.47 \pm 6.06)$ and minimum in group $A(93.67 \pm 5.74)$.In group $B$ increase in heart rate $(97.63 \pm 6.08)$ was more than group $\bar{A}$ but less than group C.In all the groups maximum rise in heart rate was after $3 \mathrm{~min}$, in group $A(101.6 \pm 6.19)$, group $B(109.2 \pm 6.37)$ and group C1 14.5 \pm 5.98$)$. Heart rate begin to return back to baseline after 3 minutes.Between groupA and $B$ changes in heart rate were statistically significant after 1 minute $(p<0.05)$ and till 5 minutes.Between group $\mathrm{B}$ and $\mathrm{C}$ changes in heart rate were statistically significant after 1 minute $(p<0.05)$ and till 5 minutes.Group $C$ and $A$ changes in heart rate were statistically significant after 1 minute $(p<0.05)$ and till 5 minutes.Thus our study suggestsFentanyl provides more significant attenuation of stress response during laryngoscopy and endotracheal intubation. Rajlakshmiet al. $2015^{[4]}$ concluded Fentanyl provides a better hemodynamic condition for laryngoscopy and endotracheal intubation. Dr Karuna Sharma et al. 2016observed that HR did not rise significantly in immediate post intubation (IPI) period and returned to baseline early with Nalbuphine and Fentanyl. With Fentanyl the heart rate touched the base line earlier (2 min).Thus the result of our study correlates with these studies.

\section{2) Systolic blood pressure(SBP)}

As shown in table 4, baseline values of mean SBP was 
comparable of the three groups with no statistically significance $(p>0.05)$. Changes in SBP were not significant after giving the study drug( $p>0.05)$.SBP increased in all groups after intubation, the increase being maximum in group $C(134.07 \pm 6.14)$ and minimum in group $A$ (120.57 \pm 5.69$)$.In group B increase in SBP(126.23 \pm 6.11$)$ was more than group $A$ but less than group $C$.The maximum increase in SBP was after $3 \mathrm{mins}$ in all the groups(A-128.77 \pm 6.27 , B-137.57 $\pm 6.06, \mathrm{C}$ $158.03 \pm 5.83$ ). Between group $A$ and $B$ changes in SBP was statistically significant from 1 minute to 5 minutes.Between group $A$ and $C$ changes in SBP was statistically significant from 2 minutes to 10 minutes.Between group $B$ and $C$ changes in SBP was statistically significant from 1 minute to 5 minutes. Thus our study indicated Fentanyl controls rise in SBP post-laryngoscopy and endotracheal intubation better than Nalbuphineand normal saline.Sharma N, et al 2014 ${ }^{[3]}$, concluded that Nalbuphine causes a greater increase in SBP post intubation as compared to Fentanyl.Branko $\mathrm{M}$ et al. studied Fentanyl and Nalbuphine for Coronary Artery Bypass Surgery. In their study during and after intubation all patients given Nalbuphine( and only one patient given Fentanyl ) required nitroglycerin to control MAP. They also found higher level of epinephrine, nor-epinephrine, vasopressin and cortisol in Group $\mathrm{N}$ in comparison to baseline value.Whereas in Group F it was within baseline values. The result of our study is comparable to study conducted by Sharma $\mathrm{N}$ et al. and Branko Met al.

\section{3) Diastolic blood pressure}

As shown in table 5,values of mean DBP were comparable of the three groups with no statistical significance $(p>0.05)$.

Changes in DBP after giving drugs and after induction were also not significant statistically(p>0.05).DBP increased in all groups after intubation with maximum increase in group $\mathrm{C}(103.5 \pm 6.10)$ and minimum in group $\mathrm{A}(93.77 \pm 6.18)$ In group $B$ increase in DBP $(98.03 \pm 5.87)$ was more than group $A$ but less than group C.DBP started returning to baseline after3 minutes in all the three group.Between group A and B changes in DBP was statistically significant after 1 minute $(p<0.05)$ and till 5 mins.Between group B and C changes in DBP was statistically significant after 1 minute $(p<0.05)$ and till 5 mins.Between group $\mathrm{A}$ and $\mathrm{C}$ changes in DBP was statistically significant after 1 minute $(p<0.05)$ and till 5 minute, it was more significant than $p$ value of $A B$ group. Thus our study shows that Fentanyl attenuated rise in DBP after laryngoscopy and endotracheal intubation more effectively than Nalbuphine and Normal Saline.Nalbuphine was more effective than normal saline in the same.

Khan et al. ${ }^{[21]}$ has compared Nalbuphine $0.2 \mathrm{mg} / \mathrm{kg}$ and Fentanyl $2 \mu \mathrm{g} / \mathrm{kg}$ as total intravenous anaesthesia with Propofol infusion in laproscopic surgery. These drugs were given 5 minutes before induction. They found significant increase in SBP and DBP in Nalbuphine group which is similar to our result . DBP after intubation increased to a maximum of 13\% in Nalbuphine versus 3\% in Fentanyl.

Aftabet al. ${ }^{[25]}$ compared Fentanyl/Isoflurane and Nalbuphine/ Isoflurane in patients undergoing elective coronary artery bypass surgery. Similar to the present study, they showed that Fentanyl/Isoflurane provided better haemodynamic stability than Nalbuphine/Isoflurane $(\mathrm{p}<0.05)$.

\section{4) Mean arterial pressure}

As shown in table 6,baseline values of mean MAP were comparable between three groups with no statistical significance $(p>0.05)$.Changes in MAP were not statistically significant $(p>0.05)$ after giving drug and after induction.MAP increased in all groups after intubation and increase was maximum with group $C(113.69 \pm 6.18)$ and minimum in group $A(102.7 \pm 5.98)$.In group B increase in MAP $(107.43 \pm 5.91)$ was less than group $\mathrm{C}$ but more than group A.MAP started to return to baseline after 3 minutes in all the three group.Between group A and B changes in MAP was statistically significant $(\mathrm{p}<0.05)$ from 1 minutes to 5 minutes.Between group $B$ and $C$ changes in MAP was statistically significant from 1 minutes to 5 minutes.Between group $A$ and $C$ changes in MAP was statistically significant from 1 minutes to 5 minutes .P values of $\mathrm{BC}$ was more than $\mathrm{AC}$ signifying more changes in MAP in group $\mathrm{C}$ than group B. Hence this study demonstrates Fentanyl is better than Nalbuphine and normal saline in attenuating the rise in MAP after laryngoscopy and endotracheal intubation.

Sharma N. et al,2014observedFentanyl is more efficacious in attenuating rise in MAP than Nalbuphine during endotracheal intubation.

Rajlakshmiet al.,2015 concluded that control of MAP is better by Nalbuphine than Fentanyl during laryngoscopy and endotracheal intubation which was statistically significant $(p<0.05)$, while in our study we found Fentanyl provides better control of MAP which is statistically significant than Nalbuphine.

\section{5) Oxygen saturation}

As shown in table 7,mean oxygen saturation remained above $98 \%$ in all the groups and there was no statistically significant variation $(p>0.05)$ at any point of interval between any of the groups.

Fentanyl is a $\mu$ agonist, it has a direct depressant action on the SA node and slows conduction of cardiac impulse to $A V$ node. It tends to slow heart rate during stimulationbylaryngoscopy whereas Nalbuphine is a $\mathrm{K}$ agonist and $\mu$ antagonist.It thus has a good analgesic potency but little potency in reducing heart rate and bloodpressure. Therefore Fentanyl controls hemodynamic stress response more efficiently than Nalbuphine during laryngoscopyand intubation.

\section{SUMMARY AND CONCLUSIONS}

1) The demographic data like age and sex of the patients were comparable in all the groups.

2) The hemodynamic stress response to laryngoscopy and endotracheal intubation in the form of increased heart rate,systolic blood pressure, diastolic blood pressure and mean blood pressure were less with Fentanyl as compared to Nalbuphine and Normal Saline.

3) Fentanyl is more efficacious in controlling the rise the heart rate and blood pressure following laryngoscopy and intubation.

4) There was no various variation in oxygen saturation in any of the groups.

5) No side effects were observed in any of the groups.

Fentanyl is more effective than Nalbuphine in attenuating hemodynamic stress response during laryngoscopy and endotracheal intubation in patients posted for general ancesthesia.

\section{REFERENCES}

1. King BD, Harris LC Greifenstein FE, Elder JD and Dripps RD: Reflex circulatory responses to direct laryngoscopy and tracheal intubation performed during general anesthesia. Anesthesiology 1951; 12:556-66.

2. Martin DE, Rosenberg H, Aukburg SJ, Bartkowski RR, Edwards MW Jr, Greenhow DE, et al. Low-dose fentanyl blunts circulatory responses to tracheal intubation. AnesthAnalg 1982;61:680-4.

3. Sharma N ,ParikhH.,Comparative study of hemodynamic response to intubation:fentanyl versus nalbuphine.Gujarat Medical Journal / August-2014 Vol. 69 No. 2,pg 48-53.

4. BhandariR.,RastogiS.,TyagiA.,JoshiA.,etal.,Attenuation of hemodynamic response to endotracheal intubation with fentanyl versus nalbuphine: $A$ comparative study.Journal of evolution of medical and dental sciences/august 2015, volume 4,issue 64,11172-11181.

5. Prasad H.,KumarR., RajagokilamR.,VardarajanV.,Comparative study of amnalgesic potential of nalbuphine versus fentanyl during general anaesthesia.International journal of contemporary medical research.october 2016,vol3/issue 10,pg2815-18.

6. Kumar M.,TripathiD.C.,Clinical evaluation of efficacy and safety of three 
different doses of fenatnyl to prevent hemodynamic stress response during laryngoscopy and intubation:Arandomised double blind clinical study. International journal of clinical anaesthesiology Int J ClinAnesthesiol 5(1): 1063.

7. AminS.,Amr Y. M.,Fathy S. M.,AlzeftawyA.E., Maternal and neonatal effects of nalbuphine given immediately before induction of general anesthesia for elective cesarean section. Saudi journal of anaesthesia 2011 Oct-Dec; 5(4): 371-375.a.

8. Tariq M.A.,IqbalZ.,Qadirullah.Efficacy of nalbuphine in preventing hemodynamic response to laryngoscopy and intubation.Journal of post graduate medical institute, Vol 28, No 2 (2014)

9. Dr.SharmaK.,Dr.AudichyaP.C.,Dr.GoyalS.,Dr.Soni K., et al. Randomized Comparison Of Tramadol, Nalbuphine And Fentanyl Used As Premedication In Attenuation Of Hemodynamic Response To Laryngoscopy And Postoperative Pain In Laparoscopic Cholecystecyomy. International Journal Of Medical Science And Clinical Inventions Volume 3 issue 72016 page no. 1968-1976.

10. MoraGonzlez D.L, RoblesCervantes JA, MoraMartnez JM, BarbaAlvarez F, et al. Hemodynamic effects of dexmedetomidine--fentanyl vs. nalbuphine-propofol in plastic surgeryJournal of anaesthesia and clinical research. 2017: 420 .

11. Russell WJ, Morris RG, Frewin D B. Changes in plasma catecholamines concentration during endotracheal intubation. BrJ Anaesth. 1981:53:837-9.

12. Fox Elizabeth J, Garry S, Hill Constance H, Villanveva Raymond, King Benton D. Complications Related to the Pressor Response to Endotracheal Intubation. Anesthesiology. 1977;44:524-25.

13. Lindgren L, YliHankala A, Randell T, M Kirvela, M Scheinin, Neuvonen. Haemodynamic and catecholamine responses to induction of anaesthesia and tracheal intubation: comparison between propofol and thiopentone. $\mathrm{Br} \mathrm{J}$ Ancesthesia 993:70 30610.

14. Stoelting RK, Blood pressure and heart rate changes during short duration laryngoscopy for tracheal intubation: influence of viscous or intravenous lignocaine. Anaesthesia Analgesia. 1978;57:197-199.

15. Robert PK, Greene LT Meloche R. Studies of anesthesia in relation to hypertension-II, heamodynamic consequences of induction and endotracheal intubation. British journal of Anesthesia. 1971;43:541-547.

16. Bruder N, Granthil C, Ortega D. Consequences and prevention methods of hemodynamic changes during laryngoscopy and intubation [abstract]. Ann Fr AncesthReanim. 1992;11:57-71.

17. Malde AD, Sarode V. Attenuation Of The Hemodynamic Response To Endotracheal Intubation: Fentanyl Versus Lignocaine, TheInternet Journal ofAnesthesiology 2007; 12(1).

18. Haq AU, Kazmi EH. Nalbuphine prevents haemodynamic response to endotracheal intubation. J Coll Physicians Surg Pak 2005; 15(11):668-670.

19. Kay B, Healy TJ. Blocking the circulatory responses to tracheal intu bation A comparison of fentanyl and nalbuphine. Anaesthesia 2007; 40(10):960-963.

20. Gupta S, Tank P. Effect of nalbuphine on haemodynamic response to orotracheal intubation. Soudi Journal of Anaesthesia $2011 ; 5(1): 2-8$.

21. Khan FA, Comparison of fentanyl and nalbuphine in total intravenous ancesthesia (TIVA). J Pak Med Assoc 2002;52(10):459-465.

22. Chawda PM, Pareek MK, Mehta KD. Effect of nalbuphine on haemodynamic response to orotracheal intubation. JAnaesthesiolClinPharmacol 2010; 26(4):458-460.

23. Ko SH, Kim DC, Song HS. Small-dose fentanyl: optimal time of injection for blunting the circulatory responses to tracheal intubation.AnesthAnalg 1998; 86(3):658-661.

24. SinatraRS\&JahrJS . Cambridge University Press : ; 2010.

25. Aftab S, Mohd R, Bokhari S, et al. Comparison of fentanyl/ isoflurane versus nalbuphine/ isoflurane in patients undergoing elective coronary artery bypass surgery. Pak J Cardiol 2005; 16(2): 83-9.

26. Barak M, Ziser A, Greenberg A, Lischinsky S, Rosenberg B.Hemodynamic and catecholamine response to tracheal intubation: direct laryngoscopy compared with fiberoptic intubation. J ClinAnesth. 2003 Mar; 15(2):132-136

27. Roberta LH \& Katherine MEAnesthesia and coexisting disease 